\title{
ciclos de investimento, crises monetárias \\ e crises sociais na gestão do padrão-ouro \\ em portugal e no brasil no século XIX: uma perspectiva comparada ${ }^{\star}$
}

\section{'investment cycles, monetary and social crisis on portuguese and brazilian gold standard in XIX ${ }^{\text {th }}$ century: a comparative perspective'}

\author{
José Tadeu de Almeida ${ }^{\star \star}$ \\ Universidade de São Paulo, São Paulo, São Paulo, Brasil
}

\section{RESUMO}

Este trabalho tem por meta resgatar alguns aspectos relacionados à gestão da estrutura macroeconômica do Brasil e de Portugal na segunda metade do século XIX, com especial enfoque às políticas monetária e cambial, intimamente relacionadas com a gestão do sistema do Padrão-Ouro, que constitui o objeto principal desta análise. Da mesma forma, pretende realizar uma reflexão a respeito dos impactos de crises econômicas sobre o sistema do Padrão-Ouro e sobre a própria ordem social, com especial atenção aos problemas relacionados ao custo de vida, à estrutura de consumo e à capacidade de inserção da população em geral no sistema financeiro, através das Caixas de depósitos, dos Montepios (em Portugal), dos Montes de Socorro (no Brasil) e outras instituições de crédito popular.

Palavras-chave: Padrão ouro-libra. Crises financeiras. Riqueza. Custo de vida. Crise de 1857.

\begin{abstract}
This paper analyses the management of Brazil and Portugal economic structures along the 2th half of XIXth century, focusing monetary and exchange rate policies, inwardly related to the management of gold standard, the main object of the paper.

Similarly, intends to make a reflection about the impacts of economic crisis over the gold standard and the social order, specially focusing the problems related to costs of living, the consumption structure and the insertion of people on the financial system, through the Caixas de depósitos and Montepios (in Portugal), the Montes de Socorro (in Brazil) and another popular credit institutions.
\end{abstract}

Keywords: Gold Standard. Financial crisis. Wealth. Cost of living. 1857 crisis.

\footnotetext{
* Submetido: 15 de outubro de 2012; aceito: 4 de julho de 2013.

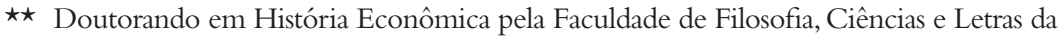
Universidade de São Paulo (FFLCH-USP).Email:josetadeu_almeida@yahoo.com.br.
} 


\section{Introdução}

O trabalho pretende, em linhas gerais, realizar uma reflexão a respeito da condução da política econômica do Brasil e de Portugal, em especial na segunda metade do século XIX, com especial ênfase sobre as dimensões monetária e cambial dentro dos marcos teóricos e práticos do modelo de paridade internacional de moedas conhecido como o Padrão-Ouro. Busca-se, assim, como objetivo geral, estabelecer um marco teórico, ainda que em caráter seminal, para discussões mais amplas e sistemáticas no que concerne à estruturação econômica desses dois países ao longo do período sob análise.

Tendo sido o Brasil um dos primeiros países a adotar o modelo, por meio da Lei $\mathrm{n}^{\circ}$. 401, de 11 de Setembro de 1846, com a paridade estabelecida para 27 pence a cada um mil-réis, observar-se-á nos anos seguintes o sucessivo esforço das autoridades monetárias em manter a taxa estável em conjunturas de crise. A título de exemplo, durante os primeiros dias do 'pânico' de 1857, a taxa caiu da paridade de 27 pence para 26, e por fim 25,5 pence para cada mil-réis; neste momento, o Banco do Brasil, visualizando a desvalorização progressiva ${ }^{1}$ da moeda nacional, suspende as operações de troca de notas de mil-réis por ouro e libras.

Por sua vez, em Portugal, o sistema entrou em operação no ano de 1854, na esteira das medidas de ordenamento do meio circulante que se sucederam aos graves conflitos sociais da década de 1840, tais como a Revolta da Maria da Fonte e a Guerra da Patuleia, bem como após a crise monetária do biênio 1846-47.

Busca-se, assim, entender a questão do Padrão-Ouro no Brasil e em Portugal não apenas enquanto instrumento de transação e câmbio com as economias centrais, mas também como uma instituição característica de um momento histórico, onde nota-se uma ênfase total, por parte dos governos de ambos os países, sobre a manutenção de um estoque de

1 Utilizando o processo inglês (upisup) para avaliação da taxa de câmbio, tem-se que, para o agente nacional, uma elevação da quantidade de moeda estrangeira necessária para adquirir uma quantidade fixa de moeda nacional indica a apreciação da moeda nacional; por outro lado, a redução do preço da moeda nacional em termos de moeda estrangeira evidencia uma desvalorização da moeda nacional. Em termos práticos, a passagem domil-réis de 27 para 25,5 pence mostra que um volume menor da moeda inglesa compra a mesma quantidade da moeda brasileira, evidenciando a desvalorização do mil-réis. 
ouro que tornasse possível às suas autoridades monetárias fazerem frente às taxas de paridade cambial exigidas pelo padrão vigente.

A 'atração metalista' associada à manutenção desses estoques, segundo o autor, poderá engendrar crises no sistema monetário nacional, que têm como resultado o esgotamento rápido das reservas internacionais, além de pressões cada vez maiores para a desvalorização da taxa de câmbio corrente.

Tal conjuntura de instabilidade recorrentemente conduzia os países signatários do sistema do Padrão-Ouro a crises de conversibilidade que engendravam profundas desvalorizações cambiais e distorciam a estrutura de preços relativos, afetando diretamente a manutenção do continuum material das economias, principalmente na órbita do comércio exterior.

Portanto, como objetivo específico, procuraremos também entender, com maior profundidade, os impactos sociais (em termos da estrutura de custo de vida da população e outras variáveis disponíveis) das crises econômicas que se verificaram em ambos os países, com ênfase na crise de 1857 (para o caso brasileiro) e nas crises de 1846-47 e 1876, para o caso português.Destarte, para a realização da reflexão proposta, é de suma importância a definição de uma metodologia para a devida consecução e compreensão dos temas.

No primeiro tópico, buscamos estabelecer marcos gerais sobre a estruturação econômica de Brasil e Portugal em meados do século XIX, com maior ênfase, conforme abordamos, sobre as dimensões monetária e cambial, e sobre a gestão do modelo do Padrão-Ouro, em ambos os países. No segundo tópico, ressaltaremos as consequências desses mecanismos de integração financeira, sobretudo no que diz respeito à formação de horizontes de instabilidade que conduziam com frequência a crises de conversibilidade; da mesma forma, procuraremos dar vulto aos impactos sociais desses momentos de crise econômica, sobretudo sobre o custo de vida da população e sua inserção - ainda que precária - nos circuitos financeiros locais.

Nesse sentido, o terceiro tópico fornecerá maiores luzes sobre este tema, à medida que se busca identificar esses 'sub-circuitos' de acumulação nos países analisados, e que estão corporificados em instituições de poupança popular e bancos de penhor, tais como a Caixa Econômica e o Monte de Socorro, no Império do Brasil, e das Caixas de Socorro, em Portugal. 
Como se percebe, por fim, este trabalho ainda possui um caráter fortemente seminal; pretendemos apenas lançar os pontos fundamentais de sinergia no desenvolvimento econômico dos dois países no período analisado, bem como prosseguir na busca por referenciais mais bem consolidados.

\section{Notas sobre a estruturação econômica de Brasil e Portugal no século XIX}

Neste tópico, pretendemos fazer alusão à conformação econômica de Portugal e Brasil a partir da adoção do regime do Padrão-Ouro.

No ocaso do século XVIII, o sistema monetário europeu começa a consolidar um processo de profundas transformações. $O$ ouro e a prata, que já possuíam o status de principais meios de troca na economia internacional, vão se tornando a base para um sistema bimetálico ${ }^{2}$.

A partir das décadas de 1840-50, o modelo bimetalista,ainda em uso em algumas das economias ocidentais, tais como a França, começa a entrar em declínio. A descoberta de grandes reservas de ouro na Califórnia e na Austrália, associada ao ato do Banco da Inglaterra já em 1816 (Coinage Act), adotando o referido metal como referência para as transações financeiras, é, conjuntamente, o marco inicial da expansão do Padrão-Ouro e da conversibilidade de moedas nas praças europeias (comandadas por Londres e Paris) e, a posteriori, sobre grande parte das economias ocidentais ${ }^{3}$.

O ingresso da economia brasileira ao regime do Padrão-Ouro, ocorrido em 1846, deve ser entendido no contexto de uma debilidade orgânica da economia nacional, que impunha ao Tesouro nacional uma

2 Ao longo dos séculos, o ouro e a prata foram utilizados como determinadores comuns das trocas e da mensuração do valor do dinheiro; em que pese o fato de o ouro ser negociado em valores bastante superiores aos da prata (eventualmente, no caso brasileiro após 1846, na razão de 15,625 moedas de prata para cada uma de ouro em circulação corrente).

3 Deve-se ter em conta, ainda, que o período entre 1848 e 1871 é permeado por uma série de revoluções armadas na Europa, o que obriga algumas economias, por vezes, a utilizar mais intensamente o papel-moeda a fim de sustentar o warfare relacionado a essas convulsões sociais - papel que, obviamente, era sujeito à depreciação (HAWTREY,1947: 70-78). 
reforma econômica que visasse fortalecer os seus estoques em moeda metálica. O gráfico 1, abaixo, ilustra este fato a partir da dimensão dos saldos orçamentários no período anterior ao do Padrão-Ouro:

Gráfico 1

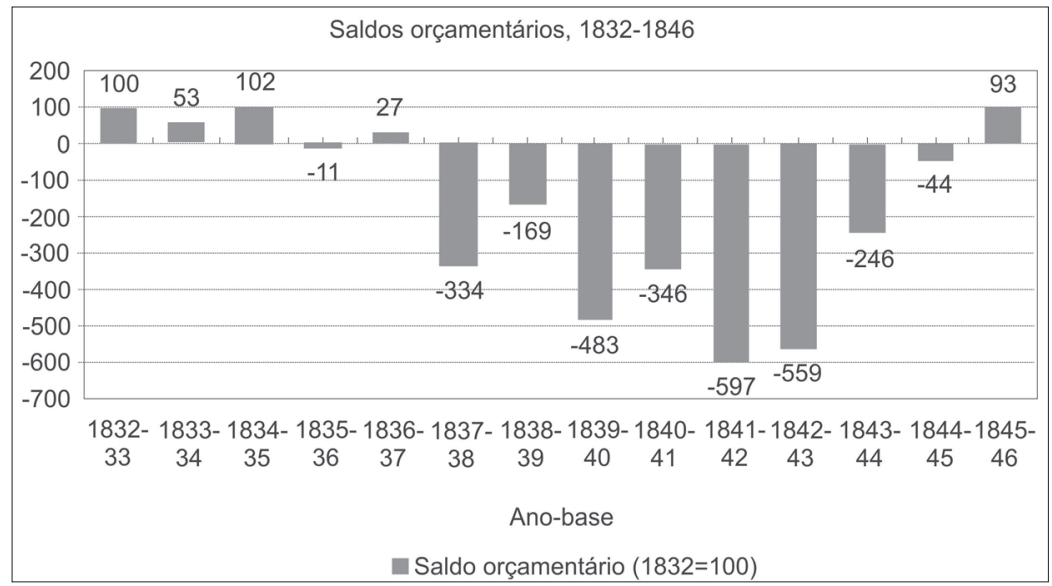

Fonte: ÓNODY, 1959: 197.

Tal debilidade pode ser observada, portanto, a partir da década de 1830. Ainda que o café já começasse a render dividendos à economia, até então não se havia evidenciado surtos de exportação do produto que pudessem acelerar o crescimento nacional ${ }^{4}$. A progressiva diminuição do ingresso de metais preciosos no 'sistema econômico' através da mineração em jazidas (as reservas da Califórnia e da Austrália ainda não haviam sido suficientemente exploradas) e a forte concorrência internacional em gêneros primários, como a cana-de-açúcar ${ }^{5}$, contribuem para uma estagnação das exportações que, juntamente com o aumento das importações de produtos, gera evasão de capitais em moeda metálica. O gráfico 2 demonstra este movimento:

4 Esse movimento seria visível a partir da década de 1850, notoriamente.

5 A este respeito, afirma Raymundo Faoro:" o açúcar de beterraba, introduzido no mercado mundial durante as guerras napoleônicas, precipita o Nordeste na crise de onde não mais sairia, senão para transitórias melhorias". FAORO, 1975: 325. 


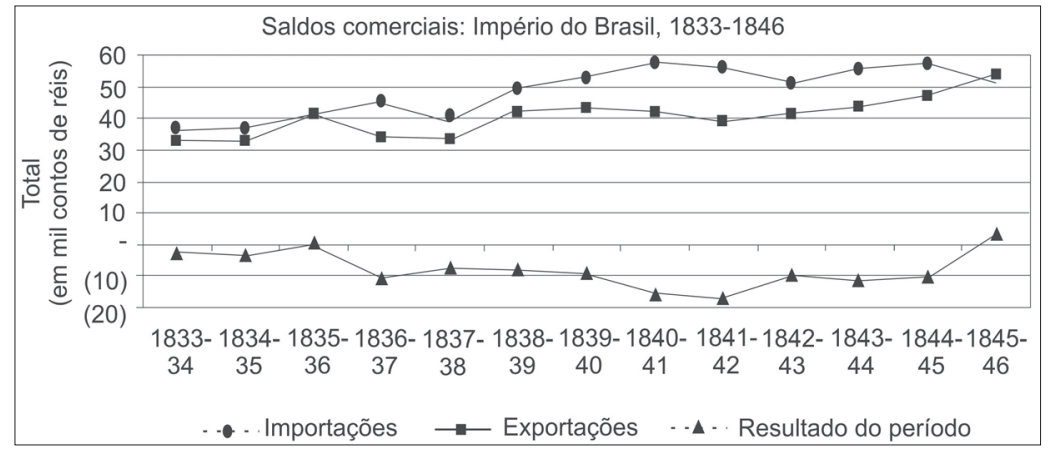

Fonte: CALÓGERAS, 1960: 63.

Em 1846, a fim de estancar a saída de capitais e fornecer maior estabilidade à moeda nacional, é sancionada a Lei n ${ }^{\circ}$. 401, em 11 de setembro, que fixa a razão de paridade a 27 pence, em ouro, a cada mil-réis. Da mesma forma, o artigo segundo da Lei determinava que o Governo Imperial estava autorizado a recolher papel-moeda na quantidade que julgasse necessária, com o intuito de manter a valorização da moeda nacional. A razão entre a prata e o ouro ficou estabelecida, a partir de 1847 , no valor de $15,625^{6}$.

Tais medidas colaborariam no sentido de tornar uniforme o sistema monetário nacional (dando menor ênfase à prata e aos outros metais na cunhagem e circulação de moedas). Poder-se-ia, assim, na abordagem de Hugon (1978), gerar bases para a retomada do desenvolvimento na segunda metade do século XIX, notoriamente sob a égide da 'economia do café'7. Portanto, por uma necessidade de estabilização da economia - e também do sistema político, após as sucessivas revoltas regionais que abalaram o período Regencial a partir de 1834 - que o sistema do Padrão-Ouro encontra terreno fértil para sua implementação na economia brasileira.

Em Portugal, percebe-se que é também a necessidade de estabilização que cria parte das condições que propiciaram a implementação do modelo Padrão-Ouro. De fato, o Reino vinha de uma série de sucessi-

6 Em ato sancionado em 1849, o governo brasileiro restringiu o lançamento adicional de moedas de prata na economia ao proibir as operações governamentais com o referido metal com valores superiores a vinte mil-réis (VIANA, 1999: 308).

7 HUGON, 1978: 145. 
vas revoltas e guerras civis, notoriamente a partir de 1828, com as Guerras Liberais entre D. Pedro IV (D. Pedro I do Brasil) e D. Miguel, a Revolução da Maria da Fonte e a Guerra da Patuleia ${ }^{8}$.

Mais que isso, porém, deve-se verificar que uma série de circunstâncias, ou 'acidentes da História', conforme aborda Jaime Reis (1994), também são fatores condicionantes da emergência do Padrão-Ouro em Portugal. Dentre elas, cabe citar o transbordamento de ouro nas praças europeias, como fruto das descobertas de novas jazidas no começo da década de 1850; essas descobertas abasteceram o mercado com o metal e facilitaram seu uso progressivo como meio de troca.

E ainda, pensando pelo lado do comércio internacional, tem-se que Portugal mantinha, ainda neste período, fortes laços comerciais com a Grã-Bretanha: o gráfico 3, na página seguinte, demonstra essa tendência. A participação expressiva inglesa na estrutura portuguesa de exportações trazia, como decorrência, a adoção da libra esterlina como moeda-chave do comércio internacional; a fixação do Padrão-Ouro, lastreado sobre a libra, poderia facilitar a paridade entre a moeda local, o real, e a libra esterlina, com resultados favoráveis aos comerciantes de exportação.

Contudo, não se pode desconsiderar que tal estrutura de comércio embutia, em momentos anteriores, severas desigualdades, com potenciais resultados no futuro: de fato, até 1837, os produtores locais de gêneros alimentícios pagavam tarifas ad valorem de até $33 \%$, ao passo que os produtos importados não recebiam qualquer tipo de oneração até 1817, sob o argumento de evitar o risco de desabastecimento com gêneros de outros países.

E, não obstante a participação inglesa nas exportações portuguesas ser alta, pelo lado oposto essa situação não se verificou: apenas 1\% das exportações inglesas se dirigia a Portugal; esta posição menor na pauta reduzia a capacidade portuguesa de forçar tarifas competitivas e tratados de comércio com os ingleses, pelo que se observa um decréscimo nas exportações portuguesas a partir da década de 1870, tanto por conta da concorrência internacional, que prejudicava os interesses portugueses em torno de seus principais produtos, quanto por conta de sua relativa baixa agregação de valor, dado que a maior parte das exportações era configurada por gêneros agrícolas.

8 PEREIRA, 1979: 388. 


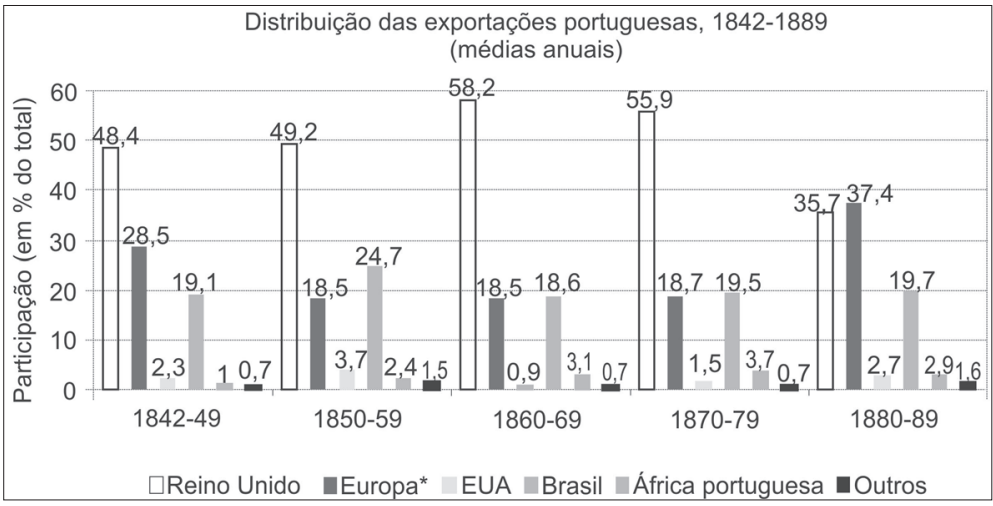

Fonte: LAINS, 2003: $77^{9}$

Em 1854, é realizada a reforma monetária que implementaria em Portugal o regime do Padrão-Ouro: definiu-se o valor da moeda oficial (real) por 1,626mg de ouro. Da mesma forma, foram fixados os tipos de moedas que poderiam ser cunhadas pela Casa da Moeda, com quantidades fixadas por lei e em valores entre 50 réis (meio tostão) e 10 mil-réis (coroas). Por fim, confirmou-se o curso legal de moedas britânicas em Portugal, paralelamente à moeda portuguesa (soberanos e meio-soberanos, nos valores de 4500 e 2250 réis, respectivamente) ${ }^{10}$.

À guisa de encaminhamento para a próxima seção do trabalho, é possível inferir que, no que diz respeito às economias brasileira e portuguesa em meados do século XIX, pôde-se verificar que elas apresentam um certo 'pioneirismo' ao abraçarem o sistema do padrão-ouro já em 1846 e 1854, respectivamente, quando grande parte das economias centrais ainda não o tinha feito, ou, ao menos, ainda não o tinha feito de jure.

O sistema do padrão-ouro tem sua relevância, nesta linha de análise, não só no sentido de engendrar uma necessidade de estabilização monetária nas economias ocidentais, favorecendo o incremento do comér-

\footnotetext{
9 O termo 'Europa ${ }^{\star}$ ' corresponde à soma das exportações portuguesas para uma série de países selecionados, a saber: Espanha, França, Itália, Alemanha, Bélgica, Suécia e Noruega, e Rússia.

10 DUARTE \& ANDRADE, 2003: 2.
} 
cio internacional, ou pela necessidade de se evidenciar um interesse nítido dos credores internacionais em manter a solvência das economias que haviam contraído empréstimos durante o boom de capitais da década de 1840.

Durante o processo de coordenação, porém, a política econômica desses países, ainda que seja um tanto quanto ousado afirmar que tenha sido 'harmoniosa', visava não só defender a paridade de suas moedas, bem como evitar desequilíbrios no balanço de pagamentos que conduzissem ao endividamento excessivo frente ao volume do produto interno.

Contudo, é importante manter no horizonte a ideia de que ambas as economias operavam com uma pauta exportadora formada, em grande medida, por gêneros primários, de baixo valor agregado. Esta pauta contribuía, efetivamente, para tornar a economia em grande parte vulnerável a ciclos de preços, a despeito do processo de coordenação e, pode-se ainda dizer, de centralização das finanças nacionais, concentrando o processo decisóriotrazido pelas regras do Padrão-Ouro sobre as autoridades monetárias, tal como afirma Barry Eichengreen:

os países produtores de commodities estavam sujeitos a abalos excepcionalmente fortes nos preços de seus produtos no mercado. Muitos haviam se especializado na produção e exportação de uma pequena diversidade de produtos primários, o que os deixava expostos a flutuações voláteis de seus termos de troca. Os países na periferia também sofriam os efeitos desestabilizadores de mudanças nos fluxos de capital internacionais. No caso da Grã-Bretanha e, em menor medida, no de outros credores europeus, um aumento dos empréstimos externos poderia provocar um desequilíbrio na balança do comércio de mercadorias (EICHENGREEN, 2000: 68).

\section{Efeitos da integração financeira: crises cambiais e impactos sociais}

Nesta seção do trabalho, pretendemos realizar algumas reflexões a respeito do desenvolvimento das economias brasileira e portuguesa nos momentos que se sucedem às suas adesões ao modelo do Padrão-Ouro. Como será possível verificar, na década de 1850 a trajetória assumida pelos dois países assume uma conotação relativamente semelhante, ao menos no que diz respeito ao fomento a investimentos em infraestru- 
tura (como ferrovias e iluminação pública) e ao desenvolvimento de um "sistema bancário" ${ }^{11}$, ainda que sujeito a crises de confiança e reversões constantes de expectativas por parte dos diversos investidores, tal como ocorreu no Brasil no ano de 1857.

Por outro lado, tomando por base a dimensão política, é possível verificar que em meados do século Portugal e Brasil experimentavam movimentos reformistas, ainda que diferenciados em termos de atores e orientações partidárias: no Brasil, perceber-se-á a hegemonia do Partido Conservador a partir de 1853, com o advento dos Gabinetes da Conciliação. Em Portugal, a liderança do Partido Regenerador perpassa porção significativa do período da Monarquia Constitucional (1820-1910).

Ambos os partidos conseguiram, tanto quanto possível, acomodar interesses das mais diversas facções político-partidárias, como forma de possibilitar o desenvolvimento nacional. Esta seção do trabalho, portanto, pretende realizar maiores explanações a respeito da estruturação política de ambos os países ao longo do período analisado, a fim de verificar os impactos das mais diversas ações políticas sobre a própria vida econômica.

No tocante à estruturação política do Brasil na década de 1850, observa-se que o fim da Revolta Praieira em Pernambuco, o progressivo afastamento dos liberais mais exaltados com a dissolução da Câmara em 1849, bem como o isolamento dos quadros conservadores mais radicais, como se evidenciará, esvaziam o movimento de oposição no âmbito do Parlamento.

11 A título de nota explicativa, é importante enfatizar que o termo 'sistema', utilizado ao longo deste trabalho para exemplificar o surgimento e a maturação de uma série de estabelecimentos bancários em ambos os países, embute algumas tensões. A primeira delas reside sobre o fato de não haver uma expressiva relação entre essas casas, tal como nos sistemas contemporâneos, através de mecanismos como câmaras de compensação de cheques, além de janelas e taxas de redesconto (a própria inexistência de um Banco Central, ainda, precipita desta descoordenação). Como consequência, o 'sistema' era significativamente vulnerável e sujeito a choques e reversões contínuas de expectativas por parte dos agentes. Contudo, como foi possível verificar processos seminais de coordenação de políticas para o setor bancário - exercidos no caso brasileiro, por exemplo, à época, pelo Banco do Brasil e por casas privadas de maior porte, como a Mauá, McGregor \& Cia - e de relações entre casas privadas em momentos de contração da base monetária, mantivemos, na medida do possível, o termo 'sistema bancário'. (FERNANDES, 2001: 85-86). 
Formula-se, então, a consciência coletiva de que a exaltação, a revolta - típica das convulsões sociais que caracterizaram o Período Regencial - e o início do Segundo Reinado (precipitado com o movimento da Maioridade, inclusive, por força dessas mesmas convulsões, que ameaçavam a integridade da nação recém-soberana), eram danosos aos interesses da nação. Passado o período revolucionário, seria de suma importância o congraçamento dos diferentes quadros que compunham o Poder Legislativo, com vistas à promoção do progresso e do desenvolvimento do país.

Não conviria, porém, ao sistema representativo que existisse unanimidade de pensamento, tal como no caso da Câmara (com 100\% dos deputados pertencendo ao Partido Conservador), em detrimento da expressão das várias opiniões existentes. Tampouco que se processasse uma hegemonia dos conservadores com a eliminação do Partido Liberal: Destarte, com seus quadros fora do poder, uma das poucas chances de sobrevivência dos liberais seria compor uma coalizão com os conservadores, formando um governo de natureza moderada, com estabelecimento de consensos sobre a condução do Estado.

Ficaria esse movimento conhecido como Conciliação, sendo corporificado nos diferentes grupos de ministros que assumiram a condução dos interesses do Estado Nacional, sob a égide do Partido Conservador, na década de 1850. Nesse momento, os Conservadores e seus rivais políticos, membros do Partido Liberal, governaram de forma relativamente coesa, tornando factível a maioria dos projetos de Estado, em que pese o fato de os Conservadores terem mantido os cargos da presidência do Conselho de Ministros até $1862^{12}$.

Nesse sentido, pensamos a emergência da Conciliação na década de 1850 como um movimento político, de fato; porém, mais que isso, como também uma estratégia de longo prazo, com um interesse fortemente voltado à consolidação do Estado Nacional, perante o iminente risco de secessão representado pelas revoltas regenciais que se tinham desencadeado em anos anteriores.

Em Portugal, por sua vez, também se observavam agitações no campo político: A implementação da Monarquia constitucional, ao menos de modo aparente, não conseguiu consolidar, no longo prazo, a estabi-

12 IGLESIAS (1997). 
lização política da nação, circunstância que se traduz em uma série de rebeliões e golpes de estado a partir de 1846 (com a Revolução da 'Maria da Fonte' e a guerra civil da Patuleia).

De fato, em 1851 ocorre uma importante insurreição militar que derruba o governo liderado por Costa Cabral, $1^{\circ}$ Marquês de Tomar. Este levante marca o início dos gabinetes de governo conhecidos pela alcunha de gabinetes de Regeneração.

A plataforma política dos grupos ligados à Regeneração estava baseada, primordialmente, em uma série de reformas nos campos administrativo e econômico; essas reformas tinham como meta maior apoiar o crescimento econômico e superar os gargalos políticos e institucionais que, de diversos modos, impediam Portugal de desenvolver-se nos marcos europeus. Formatava-se, naquele momento, uma consciência coletiva em torno da ideia de que a má governança, bem como o aparente desperdício de tempo e recursos com lutas políticas e ideológicas, tinham eliminado a vida política em Portugal, o que se traduzia em severos entraves ao crescimento econômico.

Para dar forma a tais metas, realizaram-se profundas reformas no campo institucional por meio do Ato Adicional de 1852, bem como pela redução da atividade parlamentar e da disputa político-partidária (tal como também se verificava no Brasil durante os Gabinetes da Conciliação).

Em uníssono com a discussão sobre o plano político, é possível verificar que, no plano econômico, a estabilização política dos dois países conduziu, em parte, a um surto de crescimento econômico e em investimentos significativos em infraestrutura.

Para o caso brasileiro, efetivamente, em março de 1854 é inaugurado o sistema de iluminação a gás na cidade do Rio de Janeiro e na Corte. Em abril, na praia da Estrela, é inaugurado o primeiro trecho ferroviário do país, ligando o Rio à localidade de Raiz da Serra, próxima a Petrópolis. Essa estrada, cujo capital pertencia, em grande medida, a Irineu Evangelista de Sousa, recém-nomeado Barão de Mauá, seria a primeira de uma série de concessões do Governo Imperial a grupos externos para a construção de ramais ferroviários e obras em infraestrutura, tanto a concessionários estrangeiros quanto a agentes nacionais, embora estes, via de regra, também fossem ligados a grupos estrangeiros, como no caso de Mauá, acionista da firma Mauá, Mc Gregor \& Cia ${ }^{13}$.

13 GUIMAR ÃES, 2012:152-53. 
Esses processos - a iluminação à gás e a estrada de ferro - são apenas dois indicadores de uma conjuntura de investimentos obtidos a partir da ampliação da cessão de créditos para investimentos em infraestrutu$\mathrm{ra}^{14}$.Tal ampliação propiciou o surgimento de diversas companhias cujo interesse, ao menos de acordo com a retórica oficial, residia em captar recursos para a aplicação em plantas produtivas. No entanto, em diversas situações os recursos foram percebidos pelas companhias, ainda que os projetos não tivessem saído do papel.

Nesse aspecto, eram as ferrovias e investimentos na área naval que lideravam o ranking da esfera da especulação. Em outras palavras, a partir do biênio 1854-55, na esteira do lançamento da Companhia de Iluminação, no Rio, e da primeira ferrovia, companhias surgiram no intuito de lançar ações e obter empréstimos bancários - ainda que boa parte destes recursos fosse drenada para operações no sistema financeiro ${ }^{15}$.

No caso português, o período da Regeneração é permeado de investimentos em ferrovias, pontes e outras obras de infraestrutura de transportes, que visavam, tal como verificamos anteriormente, superar os entraves históricos que impediam Portugal de obter o mesmo padrão de crescimento dos países europeus.

A gestão de Fontes Pereira de Melo sobre o Ministério das Obras Públicas denota essa visão: já no início da década de 1850, houve um expressivo aumento no número de estradas, encetou-se a construção de ferrovias (cujo primeiro trecho, entre Lisboa e a freguesia do Carregado,

14 MONT'ALEGRE, 1972: 127.

15 Entre 1851 e 1856, o Governo aprovou, por decreto, a criação de 78 companhias, com capital estimado em 156.368 contos de réis, todo este valor representado em ações negociáveis (MONT'ALEGRE, 1972: 136). Em um autor contemporâneo ao período em estudo, tem-se uma opinião negativa a respeito do início da espiral especulativa: 'Pode-se afirmar que até 1852 os commerciantes do Rio de Janeiro podião ser apontados como modelo de honradez a todos os negociantes do mundo; mas desde que a febre das emprezas por associações anonymas nos accometteu, e com ella o imoral jogo da agiotagem, sentio-se uma rápida transformação na circumpsção e critério de grande parte dos nossos negociantes, e nas outras classes sociaes a que estas aleatórias especulações se entregarão'. SOARES, 1865:11-12. E, em uma crítica mordaz, afirma José de Alencar: 'Ora, se há tempo em que a solidão seja insuportável, é este de agora, em que não se fala, não se trata, nem se pensa senão em companhia. Janta-se em companhia dos amigos, passa-se a noite em boa companhia, e ganha-se dinheiro em companhia. Nada hoje se faz senão por companhia. A iluminação a gás, as estradas, os açougues, o asseio público, a construção de ruas, tudo é promovido por este poderoso espírito de associação que agita atualmente a praça do Rio de Janeiro'. ALENCAR, 1955?:162. 
estaria pronto em 1856) e dão-se os primeiros passos na constituição de linhas telegráficas. Não obstante, no mesmo período inauguraram-se serviços regulares de navios a vapor, bem como serviços postais e outras redes de comunicação.

No que tange à estruturação bancária, pode-se verificar que seu desenvolvimento em Portugal, em meados do século XIX, possuía um sensível adiantamento em relação ao Brasil: o rápido desenvolvimento do Banco de Lisboa, na década de 1840, engendra o surgimento de sociedades dedicadas à intermediação de negócios da dívida pública, tais como a Companhia Confiança, a Companhia de Crédito Nacional e a Companhia União. Da mesma forma, duas décadas antes do Brasil, já são criadas caixas econômicas destinadas ao recolhimento de poupanças de classes menos favorecidas e ao provimento de socorros mútuos.

Por sua vez, para o caso brasileiro, será na década de 1850 que se registrará um grande incremento da atividade bancária, haja visto a reestruturação do sistema monetário brasileiro proposta com a Lei de 1846 e a fixação da paridade do mil-réis. No eixo deste novo arranjo institucional, surgem diversas casas bancárias de caráter emissionista, estimulando a tomada de créditos para o sistema produtivo ${ }^{16}$. Dentre estas, cabe citar o terceiro Banco do Brasil - haja vista que os dois primeiros foram criados em 1808 (sendo extinto em 1829) e 1851 (de duração efềmera) - bem como, nas esferas regionais, o Banco Comercial do Maranhão e o Banco Comercial da Bahia.

Com base em tais informações, é possível ter em conta que a atividade bancária em ambos os países apresentará expansão significativa no contexto da década de 1850. A evolução da política monetária, ocorrida por meio do compromisso da manutenção da paridade cambial, aliada a um aparato institucional favorável, capaz, no caso do Brasil, de facultar aos bancos supracitados (e a outros de menor expressividade) a capacidade emissora de títulos resgatáveis (ainda que se restabeleça o monopólio ao Banco do Brasil em determinados períodos), bem como aliada ao aumento significativo da demanda por créditos para a realização de inversões no sistema produtivo nacional, de caráter eminentemente agrícola, condicionam significativas oportunidades de realização de lucros nos mercados português e brasileiro.

16 TRIGUEIROS, 1987: 85-90; HANLEY, 2005: 25-27. 
Assim sendo, é inegável que essas oportunidades favoreceram uma possível dinâmica especulativa e viabilizaram, consequentemente, o surgimento de diversas casas bancárias. Essa lógica, é importante frisar, contraria o movimento de concentração do sistema bancário visível no restante do ambiente europeu, no qual alguns países passam a unificar seus sistemas na órbita nacional (como a Bélgica e, em menor vulto, a França) a fim de torná-los menos vulnerável a crises financeiras.

Contudo, é importante ressaltar que, para os casos de concentração bancária citados, verificamos que esta se dá na forma de uma regulação promovida pelo Estado, com objetivos estratégicos, que passavam pela solvência do sistema bancário e da manutenção de um horizonte de confiança aos agentes econômicos. Tratava-se, assim, de um certo marco regulatório, aparato este ainda não criado e institucionalizado no Brasil.

Chegando, portanto, ao core da seção, que se dedica a analisar as diferentes crises financeiras em Portugal e Brasil no século XIX, é possível enfatizar, a princípio, que estas nações passaram por fases de instabilidade em diferentes períodos; não há, na maioria das situações, uma crise sistêmica que afete simultaneamente as economias brasileira e portuguesa (exceção feita à crise do Baring Brothers, em 1891).

Para o caso do Brasil, a primeira grande crise financeira após o advento do Padrão-Ouro tem lugar em 1857. Charles Kindleberger manifesta uma clara posição ao afirmar que o movimento se iniciou com a falência da companhia de seguros Ohio Life E Trust Company, em 24 de Agosto do referido ano. Este fenômeno teria sinalizado aos credores e investidores que a bolha especulativa, 'ancorada' sobre companhias e movimentação de ações, estaria entrando em colapso ${ }^{17}$.

Tomados pelos conhecidos (e mesmo tradicionais) mecanismos de incerteza quanto à solvência das casas bancárias, comuns a momentos de instabilidade que se sucedem a booms de oferta de ativos financeiros, esses agentes recorreram aos bancos a fim de liquidarem suas posições de caráter especulativo e retornarem a aplicações de corte conservador. Os bancos, porém, fortemente alavancados por conta dos créditos concedidos com relativa facilidade nos anos anteriores, não conseguem fazer frente à demanda por saques e passam, progressivamente, a entrar em processo de falência.

17 KINDLEBERGER, 2000. 
A 3 de novembro, por meio do vapor Conrab, os rumores da instabilidade nos Estados Unidos chegaram ao Brasil, dando conta de que os bancos de Nova York haviam suspendido seus pagamentos ${ }^{18}$. Diante deste cenário, os credores europeus e dos Estados Unidos aqui residentes passaram a pressionar o Tesouro Nacional - e seu operador, na qualidade de emissor da moeda de curso forçado, o Banco do Brasil - a liquidar seus débitos, gerando fuga de moeda metálica e, mais do que isso, gerando embarque de mercadorias, em momentos nos quais o estoque de ouro era insuficiente para honrar as dívidas.

Mesmo após a suspensão da conversibilidade, a fuga de capitais prosseguia: os embarques de ouro para a Inglaterra, e a consequente desmonetização da economia nacional, foram frequentes durante o período. O próprio Banco do Brasil teve seus estoques, medidos em torno do montante de fundos disponíveis, bastante reduzido:

o Banco do Brasil, sendo nesta praça o único reservatório de capital monetário para a satisfação do comércio exterior, devia ser o primeiro a sofrer os resultados daqueles acontecimentos. O seu fundo disponível foi seriamente ameaçado e, de fato, dentro de dez meses, este fundo sofrera o desfalque de 4.714:123\$847, desfalque que prometia aumentar rapidamente pelos pagamentos forçados de recâmbios e pedidos de remessa por parte de credores nas praças em crise (PRADO, 1991: 243) ${ }^{19}$.

O gráfico 4 ilustra essa tendência:

18 Há que se ter em conta que o Brasil só interligou-se de forma plena com os 'centros civilizados', como afirmava o Barão de Mauá, em 1874, com a inauguração do telégrafo por cabo submarino, por iniciativa do próprio Mauá.Antes desta data, eram os paquetes e navios diversos que traziam as notícias de outras regiões do globo. Eram, em verdade, os 'paquetes', navios de linhas regulares entre o Brasil e os demais centros, que traziam as principais notícias do que estaria acontecendo nas praças internacionais (PRADO, 1991: 243).

19 Relatório do Banco do Brasil de 1858, citado por Mont alegre (1972: 147-148). 


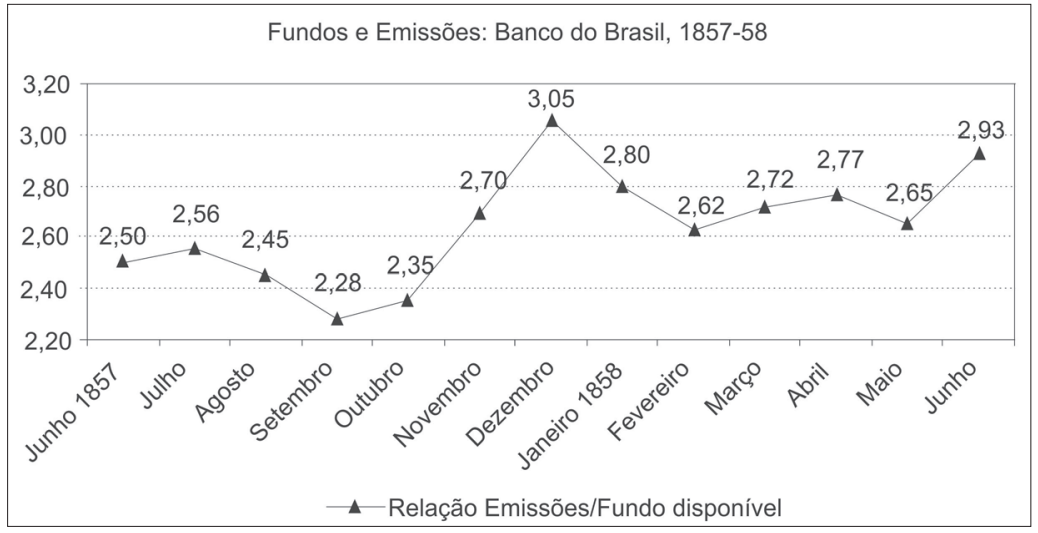

Fonte:VILELLA (1999).

A conjuntura de instabilidade começou a ser revertida apenas em meados de 1858. Neste momento, a casa bancária Mauá, McGregor \& Cia., convencida da possibilidade de restauração da paridade-ouro do mil-réis, lança com apoio do Banco do Brasil algumas letras de câmbio na praça de Londres, com valor inicial de $\mathcal{L}_{400}$.000, em março, atingindo um total de $£ 810.000$ até junho. Neste mesmo mês, os níveis de comércio foram restabelecidos na praça londrina, e o sistema bancário norte-americano já havia conseguido absorver as perdas decorrentes da quebra de bancos e companhias de crédito $^{20}$.

No Brasil, acertaram-se os últimos detalhes, em junho, para a tomada de um empréstimo de $\mathcal{E} 1,4$ milhão, para o prosseguimento das obras da Estrada de Ferro D. Pedro II. Por fim, a colheita de 1858, que elevou os preços do café no mercado internacional, também elevou a demanda por moeda internamente, o que possibilitou uma apreciação da mesma: em agosto, a taxa de câmbio havia subido para 26,55 pence para cada mil-réis, nível bastante próximo ao acordado na Lei $n^{\circ} .401$, de setembro de 1846.

Grosso modo, como impacto social, a população será afetada, sim, na dimensão do custo de vida, tratada também como o fenômeno da carestia, que passou por incremento significativo no período em análise:

20 CALÓGERAS, 1960:111. 
produtos básicos para a manutenção da vida material dos cidadãos, como farinha de trigo, bacalhau e manteiga, além de azeite de iluminação e querosene, eram importados ${ }^{21}$; em momentos de crise, a desvalorização cambial certamente contribuiria para a elevação de seus preços, o que gera impactos no custo de vida.

Colocado o problema sob perspectiva estatística, tem-se o gráfico 5 abaixo:

Gráfico 5

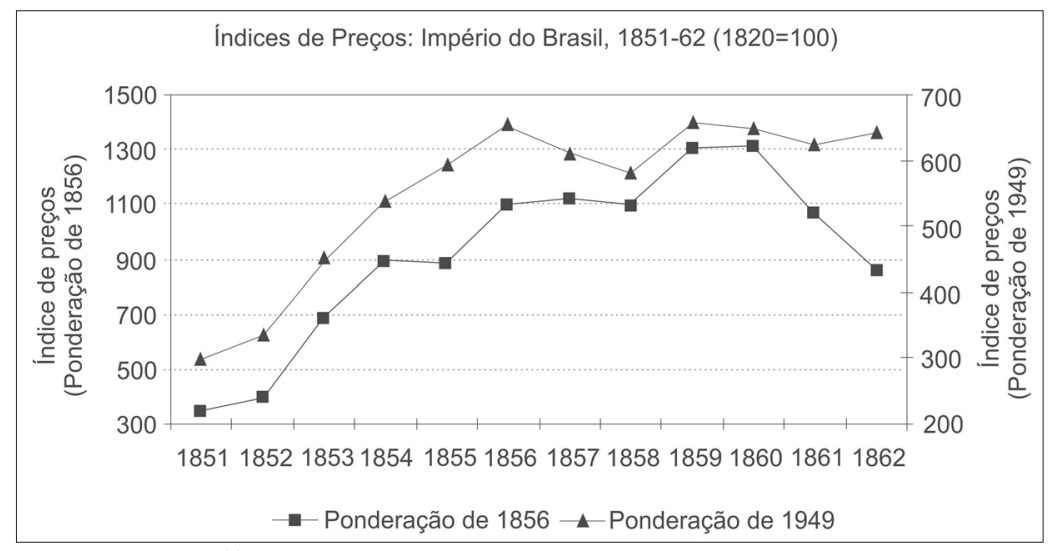

Fonte: LOBO (1971) ${ }^{22}$.

No caso português, as crises financeiras de maior vulto ocorreram em 1847 e 1876. Para o primeiro caso, tem-se que os graves distúrbios sociais decorrentes do levante da Maria da Fonte, do golpe da Emboscada e da guerra da Patuleia afetaram drasticamente as finanças portuguesas. As autoridades monetárias, nesse sentido, declararam a inconvertibilidade das notas do Banco de Lisboa em ouro, colocando-as sob curso forçado, a 29 de maio de 1846; pari passu a esta medida, recorreram aos créditos do Banco de Portugal, sob a forma de notas inconvertíveis do Banco de Lisboa, para financiar a guerra civil da Patuleia ${ }^{23}$.

\footnotetext{
21 LOBO, 1971: 238-39.

22 A ponderação de 1949 foi realizada pela Fundação Getúlio Vargas e a de 1856, pela autora, baseada em informações coletadas junto a diversas fontes primárias (inventários de empresas, instituições de benemerência, entre outras).

23

LAINS, 2002: 39-49.
} 
A desvalorização da moeda que se seguiu contribuiu para que se manifestasse o caos na circulação metálica, conforme abordam Nunes eValério (2005). Segundo os autores, os agentes econômicos passaram a entesourar moeda forte e, mais que isso, a aceitar como moeda legal, além das moedas portuguesas, notas bancárias e moedas estrangeiras. Ambos afirmam que:

o objectivo desta verdadeira Babel monetária, que era estabelecer a fluidez da circulação metálica, ficou, evidentemente, longe de ser atingido. A conjugação da crise bancária com os problemas da circulação metálica fez com que, em meados do século XIX, a circulação monetária portuguesa tivesse regredido para o nível de meados dos anos 30 do mesmo século, perdendo todo o aumento conseguido entre meados dos anos 30 e meados dos anos 40 (NUNES e VALÉRIO apud LAINS e SILVA (Org.), 2005: 288-89).

Entre as medidas adotadas pelas autoridades monetárias portuguesas com o objetivo de minorar os efeitos da crise de 1847 estão, é importante frisar, além da inconvertibilidade das notas do Banco de Lisboa, a aprovação para funcionamento do Banco de Portugal, em 1850 (com a fusão do então extinto Banco de Lisboa e da Companhia Confiança Nacional), e uma primeira reforma da circulação de moedas de ouro, em 1851, com o recolhimento de todas as moedas estrangeiras (exceto as britânicas), e sua recunhagem em novas moedas nos valores entre 1mil-réis (quinto de coroa) e 5 mil-réis (coroa).

Em 1876, advém outro momento crítico para o sistema financeiro português: o crescimento do número de estabelecimentos bancários (sobretudo bancos emissores de títulos, ainda que de menor expressividade, circunscritos ao âmbito regional, tais como o Banco União do Porto, o Banco Comercial de Braga e o Banco de Guimarães) abriu espaço, a partir de 1873, a um amplo movimento especulativo, tendo-se em conta, principalmente, que entre esta data e 1876, surgem mais 39 casas bancárias.

À medida que as expectativas dos agentes em torno da bolha especulativa se revertem e a crise se manifesta (maio de 1876), tais agentes passam a demandar o Banco de Portugal como emprestador de última instância. Em um primeiro momento o Banco conseguiu fazer frente às demandas das demais casas bancárias para sua solvência e manutenção 
de numerário. Contudo, o vencimento do prazo de carência dos empréstimos, em agosto do mesmo ano, desencadeou uma nova situação crítica: o Banco Comercial de Braga abriu falência, e o Banco Mercantil Portuense suspendeu o reembolso de seus depósitos; o Banco de Portugal, porém, não conseguiu cumprir, desta feita, seu papel de lender of last resort.

Mais que isto, houve uma corrida bancária: certos da insolvência do Banco, os seus depositantes passaram a exigir também o resgate de suas aplicações. Essa situação levou o Banco de Portugal a solicitar ao governo a inconvertibilidade de suas notas, o que configuraria, stricto sensu, um momento de quebra no regime do Padrão-Ouro em Portugal, em que pese o fato de ter sido por curto período de tempo, entre 18 e 24 de agosto de $1876^{24}$.

O enfrentamento à crise, atendendo a protocolos comuns a outros países em situações semelhantes, passou pela reorganização dos meios emissores em Portugal, centralizando a emissão fiduciária em torno do Banco de Portugal (o que se realizaria somente em 1887, em vista das pressões exercidas pelos bancos emissores da região Norte).

Como conclusão ao tópico, no que tange ao modelo do Padrão-Ouro, a adesão a tal sistema implicaria, seguramente, na necessidade de realizar um enfrentamento aos efeitos de transmissão de crises e pânicos, geradores de corridas bancárias e reordenações de expectativas dos distintos agentes envolvidos no sistema de transações internacionais.

A fórmula pluriemissionista observada no Brasil e em Portugal após a concessão do privilégio de lançamento de notas e títulos por parte de diversas casas bancárias embute duas tensões. Primeiramente, trazia um movimento de expansão do crédito que engendravacomo consequência, via de regra, um significativo aumento das importações em bens de capital e de consumo, como verificamos anteriormente; tal situação, seguramente, comprometia de forma significativa o equilíbrio do balanço de pagamentos.

Do mesmo modo, essa fórmula elevava o passivo dos bancos, ampliando suas estruturas de endividamento: a emissão de bilhetes, necessariamente, prefigurava-se maior que o total dos depósitos dos contribuintes, que por sua vez era também maior que o capital próprio das casas bancárias. Desta forma, a solicitação de resgate de depósitos e/ou

24 Idem, p. 293. 
dos títulos emitidos engendrava crises bancárias, que exauriam o capital dessas instituições, levando-as à falência e provocando crises de confiança, comprometendo a capacidade de financiamento externo das economias em análise.

O enfrentamento a tal conjuntura, portanto, viria também através da melhoria dos marcos regulatórios da atividade financeira aos movimentos especulativos que então se evidenciaram; este pensamento é mais bem abordado, em síntese, por Heitor Ferreira Lima (1978), observando o caso brasileiro (que guarda, porém, significativas semelhanças, conforme percebemos, com o desenvolvimento do sistema monetário português):

a enorme expansão do setor monetário de nossa economia, principalmente a partir de 1850, exigia apreciável massa de recursos materiais que a estreiteza ou inexistência de um sistema bancário adequado não podia atender, o que levou a iniciativa privada dos maiores centros urbanos a tentar resolver isso através de emissões particulares e organização de estabelecimentos de crédito próprio, devido ao desinteresse do poder público pelo assunto (LIMA, 1978:99).

\section{Sub-circuitos de acumulação em Portugal e Brasil}

Neste tópico, pretendemos efetuar algumas considerações a respeito dos efeitos ditos 'sociais' do processo de expansão do 'sistema financeiro’ em Portugal e no Brasil em meados do século XIX. A expressão 'efeitos sociais' deve ser entendida, nesse sentido, como o conjunto de implicações decorrentes desta integração financeira - o que inclui também os impactos das crises monetárias - nos circuitos materiais ou, em outros termos, na vida cotidiana da população.

Observamos, para efeitos práticos, o surgimento de estabelecimentos populares de crédito e poupança, como os Montepios e Caixas Econômicas, bem como presumidas oscilações no custo de vida da população em períodos determinados, a fim de levantar hipóteses sobre os referidos impactos sociais das crises econômicas.

A necessidade de oferecimento de garantias reais, em algumas situações, para a cessão de empréstimos - em outras palavras, a possibilidade de uso de bens como lastro para o suprimento de crédito - permite a regulação, por parte das autoridades monetárias, da atividade do pe- 
nhor ${ }^{25}$, nos moldes daquilo que será realizado pelo Monte de Socorro da Corte, no Rio de Janeiro; tais bens, portanto, destinar-se-iam a evitar a retomada da emissão desprovida de lastro, colaborando assim com a manutenção da paridade entre a libra e o mil-réis, conforme as regras do Padrão-Ouro.

Nesta linha de raciocínio, é possível verificar que Portugal possui uma certa vantagem em relação ao Brasil, no que diz respeito à implementação de estabelecimentos destinados ao recolhimento de poupanças das classes menos abastadas. Prova disto é a criação de caixas econômicas, como a anexa ao Montepio Geral, já em 1844, ou seja, mesmo antes da implementação do regime do Padrão-Ouro. Na década de 1870, surgiriam outras instituições que também captavam somas de particulares, como a Caixa Geral de Depósitos $(1876)^{26}$.

No Brasil, dada à natureza restritiva (e até certo ponto elitista) do setor bancário brasileiro no Segundo Reinado - cujas cláusulas de exigibilidade de fundos por parte dos correntistas eram capazes de superar, em larga escala, os ganhos médios percebidos pela população local - é preciso considerar a inexistência, ao menos até 1860, de mecanismos estatais com viés 'popular' no que toca à cessão de créditos e formação de poupanças; em outros termos, não se verifica uma bancarização da população. É neste contexto que surge a Caixa Econômica e Monte de Socorro na Corte, no Rio de Janeiro.

A Caixa Econômica da Corte foi implementada oficialmente pelo Decreto $n^{\circ} 2.723$, de 12 de janeiro de 1861. Em seguida, promulga-se o regulamento da instituição:

Regulamento da Caixa Econômica

Capítulo I

Das funcções da Caixa Econômica.

Art. $1^{\circ}$ A Caixa Econômica estabelecida na Cidade do Rio de Janeiro (...) tem por fim receber a juro de $6 \%$, as pequenas economias das classes menos abastadas, e de assegurar, sob garantia do Governo Imperial, a fiel restituição do que pertencer a cada contribuinte, quando este o reclamar.

Art. $2^{\circ}$ : As sommas recebidas pela Caixa serão sempre de $1 \$ 000$ ou de múltiplos desta quantia; e as entregues em cada semana pelo mesmo indi-

\footnotetext{
25 Do francês pignorem, 'ato ou palavra que assegura o cumprimento de um compromisso'.

26 Para uma obra abrangente sobre a Caixa Geral de Depósitos, ver LAINS (2002).
} 
viduo nesta e em qualquer outra Caixa garantida pelo Governo, segundo

a Lei de 22 de Agosto de 1860 , não poderão exceder a $50 \$ 000$.

O 'cofre seguro das classes menos favorecidas', conforme aludia o Visconde do Rio Branco, possui quatro precedentes de suma importância para a compreensão de seu desenvolvimento. Primeiramente, em sintonia com as reflexões previamente realizadas, está o fato de esta instituição aceitar depósitos de pequena monta.

Em segundo lugar, as garantias de remuneração dos depósitos - à média de $6 \%$ ao ano - eram semelhantes à taxa praticada pelo Tesouro para o pagamento dos seus compromissos de dívida externa; os depósitos na Caixa, portanto, convertiam-se em uma alternativa de investimento com rentabilidade bastante semelhante à obtida pelos grandes investidores na compra de apólices do Governo Brasileiro, situação que era, indubitavelmente, favorável àqueles agentes que fossem avessos ao risco, sobretudo em uma conjuntura de instabilidade após os acontecimentos dos anos anteriores.

Em terceiro, é importante citar que a Caixa oferecia, não obstante, total garantia do Governo Imperial para a restituição dos depósitos de seus clientes, preservando-a de corridas bancárias e momentos de reversão de expectativas que pudessem engendrar a quebra do banco: o fato de ser uma companhia de capital fechado também atuava como fator adicional de segurança aos agentes. Por fim, a Caixa abre um precedente inédito à medida que aceita também depósitos de escravos, em que pese o fato de que os mesmos devessem sempre ter o nome de seus senhores constando em suas cadernetas.

O regulamento do Monte de Socorro, por sua vez, traz em seu bojo algumas mudanças em relação à Caixa:

Das funcções do Monte de Soccorro.

Art. $1^{\circ}$ : o Monte de Soccorro estabelecido nesta Cidade (...) tem por fim emprestar por módico juro, e sob penhor, as sommasnecessarias para soccorrer as urgentes necessidades das classes menos favorecidas da fortuna.

Art. $2^{\circ}$ : O Monte de Soccorro não poderá fazer outras operações senão as de receber dinheiro a premio, e emprestar sob penhor por módico juro.

Art. $3^{\circ}$ : Provisoriamente não aceitará o Monte de Soccorro outros penhores que não sejão os de ouro, prata ou diamantes.

(...) 
Art. $7^{\circ}$ : O Monte de Soccorro não emprestará qualquer quantia a pessoa que não seja conhecida, domiciliada na cidade, ou que se não apresente acompanhada de um abonador.

Art. $9^{\circ}$ : Não serão admittidos, como depositantes ou abonadores, os menores, escravos, e mais indivíduos que não tiverem a livre administração de sua pessoa e bens.

Observa-se, assim, que o Monte de Socorro destinava-se a oferecer, em resumo, empréstimos à população que ocupava estratos inferiores de renda no espaço da Corte e adjacências; trata-se nesse sentido, juntamente com a Caixa Econômica, de uma primeira iniciativa no sentido de amealhar as classes 'menos favorecidas da fortuna' e integrá-las aos circuitos de acumulação (que não haviam sido rompidos sequer com as crises que se estudam neste trabalho), ainda que com montantes bastante inferiores ao que eram operados por comerciantes, empresários e outros especuladores ${ }^{27}$.

\section{Considerações finais}

Procuramos, ao longo deste trabalho, traçar alguns paralelos a respeito do desenvolvimento econômico de Brasil e Portugal no século XIX, considerando primordialmente os efeitos da adesão destes países ao regime cambial do Padrão-Ouro, e a consequente integração com as economias 'centrais'. Por tratar-se de uma perspectiva comparada e ainda perpassada de forma preliminar, não pretendemos, de modo algum, encerrar o tema neste trabalho, mas sim utilizá-lo como embasamento analítico para posteriores discussões e argumentações.

O exame das fontes primárias e a revisão da bibliografia pertinente ao tema permitiram inferir algumas conclusões, enfatizando duas dimensões, a saber: o setor financeiro e a política econômica.

Primeiramente, cabe enfatizar que a economia portuguesa, ao integrar-se ao sistema do Padrão-Ouro, detinha um nível mais avançado de desenvolvimento de suas instituições financeiras que o Brasil: efetivamente,já na década de 1840 surgem instituições populares de depósitos,

27 Para uma interessante análise sobre o florescimento da Caixa Econômica no período do Império, a partir de 1860, ver BUENO (2002). 
como os Montepios e Caixas Econômicas; no Brasil, o desenvolvimento do sistema bancário se daria a partir de 1853, sete anos após a adesão ao Padrão-Ouro, a partir do lançamento da Lei Bancária; instituições populares de crédito e depósito surgiriam apenas em 1861.

Em decorrência desse processo, o Banco de Portugal, ao atuar efetivamente como emprestador de última instância, conseguiu absorver, tanto quanto possível, os efeitos mais danosos das crises cambiais, em 1847 e 1876. No Brasil, o Banco do Brasil também atuou como lenderoflast resort, principalmente durante o período imediato após novembro de 1857, porém contando também com o apoio de importantes agentes privados, como Banco Mauá, McGregor e Cia, para a obtenção de créditos, junto às praças inglesas, para a manutenção da solvência do sistema bancário como um todo.

Da mesma forma, é possível perceber que, no caso português, há uma orientação mais clara em termos de política econômica: em Portugal, o período conhecido como fontismo, onde a liderança ativa de Fontes Pereira de Melo traduziu-se em um programa maciço de obras públicas e investimentos em infraestrutura, evitou, sensivelmente, que o Reino experimentasse uma situação de atraso ainda maior em relação aos seus pares na Europa, sobretudo após as guerras liberais da década de 1830, as revoltas populares da década de 1840 e a significativa instabilidade político-militar subsequente.

Para o caso brasileiro, por sua vez, o exame das fontes permitiu observar uma contradição no campo político com nítidos reflexos sobre a economia no período do Padrão-Ouro, qual seja, entre a necessidade de expansão de gastos do governo com as províncias (atendendo às demandas de suas respectivas elites e complexos econômicos), em um esforço de descentralização, e a preservação da associação financeira com as praças centrais, notoriamente a City londrina (e seus principais agentes, como a Casa Rothschild). Os diferentes gestores das finanças do governo atuavam, portanto, acomodando esses distintos interesses. Todavia, durante o período analisado, esse esforço de acomodação no Brasil não perdeu, de modo algum, a orientação principal, qual seja, o interesse estratégico de longo prazo, que residia na construção - de maneira centralizada - do Estado brasileiro no século XIX. 


\section{Referências bibliográficas}

ALENCAR, José de. Ao correr da pena. Prefácio de Francisco de Assis Barbosa. 4.ed. São Paulo: Melhoramentos, [1955?].

ALMEIDA, José Tadeu de. Ciclos de investimento e vulnerabilidade financeira no Brasil-Império: 1857-1864. In: Simpósio de Pós-Graduação em História Econômica, 2008, FEA/USP. Resumo dos trabalhos. São Paulo: [s.n], 2008.

. Transição política e política econômica no Brasil-Império: 1853-1862. Dissertação (Mestrado em História Econômica). Campinas: IE/UNICAMP, 2010.

BASTOS, Pedro Paulo Zahluth. A dependência em progresso: fragilidade financeira, vulnerabilidade comercial e crises cambiais no Brasil (1890-1954). Tese - (Doutorado em Economia) - Instituto de Economia da Universidade Estadual de Campinas, Campinas, 2001.

BORDO, Michael; KYDLAND, Finn E. The gold standard as a commitment mechanism. In BAYOUMI, Tamim; EICHENGREEN, Barry J; TAYLOR, Mark P. (Orgs). Modern Perspectives on the gold standard. Cambridge: CambridgeUniversity Press, 1996.

BUENO, Eduardo. Caixa: Uma História Brasileira. Porto Alegre: BuenasIdéias/Metalivros, 2002.

CALÓGERAS, João Pandiá. A política monetária do Brasil. São Paulo: Companhia Editora Nacional, 1960.

CARREIRA, Liberato de Castro. História financeira e orçamentária do Império do Brasil. Brasília, DF: Senado Federal, 1980.

Coleção de Leis do Império do Brasil. Diversos anos.

Coleção de Decisões do Império do Brasil. Diversos anos.

COTTRELL, P. L. British overseas investment in the ninetenth century.Londres: Macmillan, 1975.

DUARTE, António Portugal; ANDRADE, João Sousa. O funcionamento do Padrão-Ouro em Portugal: Análise de alguns aspectos macroeconômicos. Disponível em $<$ http://www4.fe.uc.pt/portugal/docs/apresentacao_padrao_ouro_antonio_portugal_sousa_andrade.pdf>.Acesso em 24/07/2010.

EICHENGREEN, Barry J. A globalização do capital: uma história do sistema monetário internacional. São Paulo: Editora 34, 2000.

FAORO, Raymundo. Os donos do poder: formação do patronato político brasileiro. 2.ed. Rio de Janeiro: Globo, 1975.

FERNANDES, Suzana Cristina. Amaro Cavalcanti e a luta pela industrialização brasileira. Dissertação - (mestrado em História Econômica) - Campinas: Instituto de Economia da Universidade Estadual de Campinas, Campinas, 2001.

GAMBI, Thiago Fontelas Rosado. O Banco da ordem: política e finanças no Império Brasileiro (1853-66). Tese (Doutorado em História Econômica) - São Paulo: FFLCH/ USP, 2010.

HANLEY, Anne. Native Capital: Financial Institutions and Economic Development in São Paulo, Brazil, 1850-1920. Stanford: Stanford University Press, 2005. 
HAWTREY, R.G. The Gold standard in theory and pratice. Londres: Longmans, Green \& co., 1947.

HUGON, Paul. A moeda: introdução à análise e às políticas monetárias e à moeda no Brasil. São Paulo: Pioneira, 1978.

IGLESIAS, Francisco.Vida Política, 1848-68. In HOLLANDA, Sérgio Buarque (Org.). História Geral da Civilização Brasileira, v.2, t.3. São Paulo: Difel, 1982.

KINDLEBER GER, Charles P. Manias, pânico e crashes: um histórico das crises financeiras. Rio de Janeiro: Nova Fronteira, 2000.

LAINS, Pedro. História da Caixa Geral de Depósitos 1876-1910: Política e Finanças no Liberalismo Português. Lisboa: Imprensa de Ciências Sociais, 2002.

. A economia portuguesa no século XIX. Lisboa: Imprensa Nacional da Casa da Moeda, 1995.

LIMA, Heitor Ferreira. História do Pensamento Econômico no Brasil. 2.ed. São Paulo: Companhia Editora Nacional, 1978.

. História político-econômica e industrial do Brasil. São Paulo: Companhia Editora Nacional, 1976.

LOBO, Eulália M. Lahmeyer et.al. Evolução dos preços e do padrão de vida no Rio de Janeiro, 1820-1930 - resultados preliminares. Revista Brasileira de Economia, Rio de Janeiro, v.25, n.4, pp. 235-265, out/dez.1971.

MONT'ALEGRE, Omer. Capital \& Capitalismo no Brasil. Rio de Janeiro: Expressão e Cultura, 1972.

NUNES, Ana Bela;VALÉRIO, Nuno. Moeda e Bancos. In LAINS, Pedro; SILVA, Álvaro Ferreira (orgs.). História Econômica de Portugal 1700-2000, v.2. Lisboa: Imprensa de Ciências Sociais, 2005.

ÓNODY, Oliver. A inflação brasileira (1820-1958). Rio de Janeiro: [s.n], 1960.

PEREIRA, Mirian Halpern. Revolução, Finanças, Dependência externa (de 1820 à convenção de Gramido). Lisboa: Sá da Costa Editora, 1979.

PRADO, Luiz Carlos ThadeuDelorme. A Economia Política das Reformas Econômicas da Primeira Década Republicana. Análise Econômica da Faculdade de Ciências Econômicas da UFRGS, Porto Alegre, n.39, mar/2003.

REIS, Jaime. Aspectos da História Monetária Portuguesa na segunda metade do século XIX. In Análise Social, Lisboa, vol. XXIX, 1994.

SOARES, Sebastião Ferreira. Esboço; ou primeiros traços da crise commercial da cidade do Rio de Janeiro em 10 de setembro de 1864. Rio de Janeiro: Eduardo \& Henrique Laemmert, 1865.

TRIGUEIROS, Florisvaldo dos Santos. Dinheiro no Brasil. Rio de Janeiro: Léo Christiano Editorial, 1987.

VIANA,Victor. O Banco do Brasil: Sua formação, seu engrandecimento, sua missão nacional. Rio de Janeiro: Typhographia do Jornal do Commercio, 1927.

VILLELA, André A. The politicaleconomyofmoneyand banking in Imperial Brasil: 1850-1870. Tese - (DoutoradoemEconomia) - London School of Economics and Political Science, Londres, 1999. 
VILLELA, André A. TEMPOS DIFÍCEIS: Reações às crises de 1857 e 1864 no Brasil. In III Congresso Brasileiro de História Econômica e IV Conferência Internacional de História de Empresas, 2001, Curitiba. Resumo dos trabalhos. Curitiba: [s.n], 1999. 